ORION, Vol. 14, No. 1/2, pp. 37-56

ISSN 0259-191-X

\title{
WISSELBOUSTELSELS IN DIE SWARTLAND
}

\author{
H.C. DE KOCK en S.E. VISAGIE \\ Departement Toegepaste Wiskunde \\ Universiteit van Stellenbosch \\ Suid-Afrika
}

\section{ABSTRACT}

In the Swartland region farmers do not plant wheat exclusively. There are a lot of reasons for this. The main reason is that farmers who plant only one crop will end up with a situation where they will have to buy so much fertiliser that they would not be able to make any money. Every crop influences the crops on the same land later on. It is up to the farmer to decide what the influence will be. That means it is up to the farmer to decide what crop to plant on what land. The farmer ends up rotating a certain number of crops on his land. This rotation of crops is called a rotary crop system. In this situation arises the problem of what sequence of crops should be planted to ensure an optimal income to the farmer without exhausting the land. The problem could be solved by means of linear programming (LP). This problem, however, seem to get very large as the number of crops as well as the number of years over which the problem is solved is increased. By assuming that the influence of crops are only for three years and by restricting the number of years over which the problem is solved the problem is greatly reduced. If we look at the dual of the problem we find a further reduction. The solution of the dual problem also leads to the formulation of strategies. If we formulate the problem by means of the above mentioned strategies the problem reduces to a linear programming probiem with only one constraint (which is the knapsack problem). The solution of this knapsack problem with help of a little game theory is then used in a computer program to assist farmers in deciding which crops to plant.

\section{OPSOMMING}

In die Swartland word baie meer gewasse as net koring verbou. Dié gewasse kan in baie verskillende kombinasies geplant word. 'n Sekere gewas beïnvloed die gewasse wat daarna op 'n spesifieke oppervlak geplant word. In hierdie situasie ontstaan die probleem van watter volgorde van gewasse ' $n$ optimale opbrengs sal lewer. Die probleem kan met behulp van lineêre programmering (LP) gemodelleer word. Deur na die duale probleem te kyk kan die dimensies van die probleem baie verklein word. Die oplossings van die duale probleem gee aanleiding tot die formulering van die probleem in terme van strategieë. Hierdie formulering 
vereenvoudig die probleem nog verder tot 'n LP met net een beperking (nl. die rugsakprobleem).

\section{INLEIDING}

In die onlangse verlede het boere in die Swartland omgewing uitsluitlik koring geplant. Die rede hiervoor is heeltemal voor die handliggend as in ag geneem word dat koring 'n baie hoë inkomste per oppervlak lewer. Die een groot nadeel aan hierdie boerderypraktyk (monokultuur) is die toename in onkruide en ander siektes. Boere het, in die verlede, die probleem redelik goed met behulp van chemiese middels onder beheer gehou. Hierdie gifstowwe het egter in die afgelope paar jare so duur geword dat die boere se inkomste uit koring al kleiner en kleiner geword het. In sommige gevalle het die onkoste aan gifstowwe hoër geword as die prys van die grond self. Om die probleem nog erger te maak, is daar sekere onkruide wat geneties baie na aan koring is. Dit is feitlik onmoontlik om ' $n$ chemiese middel te kry wat so 'n onkruid kan doodmaak sonder om die koring te beskadig. As so 'n chemiese middel wel beskikbaar is, is dit baie duur. Hoe nader die onkruid (geneties) aan die koring is, hoe duurder word die gifstof. Die rede hiervoor is die groot hoeveelheid navorsing wat gedoen moet word om hierdie gifstowwe, wat uiters spesifiek is, te ontwikkel. 'n Ander nadeel van monokultuur is dat die grond uitgeput word. Die probleem kan oorkom word deur kunsmisstowwe te gebruik. Soos in die geval van gifstowwe het kunsmis ook al duurder geword. Die boere was dus verplig om alternatiewe metodes te ondersoek om die probleem op te los.

Een alternatief is die gebruik van een of ander wisselboustelsel. Dié boerderypraktyk beteken dat die boer die gewasse wat op 'n spesifieke stuk grond geplant word, afwissel. Die groot voordeel van so ' $n$ stelsel is dat ' $n$ gewas opgevolg kan word deur 'n gewas wat geneties baie ver verwyder van daardie gewas is. Die onkruid wat geneties na aan die eerste gewas is, sẻ koring, kan relatief goedkoop bestry word gedurende die periode wat die tweede gewas, sê klawer (wat geneties ver van koring verwyder is) verbou word. In die periode wat koring verbou word, kan die onkruide wat geneties na aan die klawer is weer relatief goedkoop bestry word. As 'n gewas soos klawer gekies word, ontstaan verdere voordele. Die klawer variëteite plaas stikstof terug in die grond, wat 'n besparing op kunsmis meebring. Verder is klawer se saad van so 'n aard dat dit na so lank as twee jaar kan ontkiem, wat 
impliseer dié gewas kan na so lank as twee jaar hervestig word, sonder enige insetkoste. Dit bring 'n groot besparing op insetkoste mee.

Daar is ' $n$ hele aantal gewasse wat in so ' $n$ wisselboustelsel gebruik kan word - dit gee aanleiding daartoe dat baie verskillende wisselboustelsels gebruik kan word. Die vraag wat ons probeer beantwoord is watter volgorde van gewasse in so 'n wisselboustelsel 'n optimale opbrengs sal lewer. Om die probleem sinvol op te los, moet 'n paar aannames gemaak word:

- Die wins, in reële terme, bly dieselfde gedurende die tydperk waaroor die probleem opgelos word. Dit impliseer dat die kostekoëffisiënte in die wiskundige model konstant bly.

- Aanvaar dat elke jaar 'n gemiddelde jaar is. Die risiko as gevolg van weerstoestande word dus buite rekening gelaat. Die ondersoek na risiko faktore val buite die bestek van hierdie studie.

- Die wins wat uit 'n gewas gemaak word, is afhanklik van die gewas self, asook afhanklik van die gewas wat die vorige jaar op dieselfde grond geplant was. Dit is verder ook afhanklik van die gewas wat twee jaar vantevore op dieselfde grond gegroei het. Ons aanvaar dus dat 'n gewas wat drie jaar vantevore op dieselfde grond gegroei het geen invloed op die huidige oes het nie. In dié verband het Wasserman [3] die volgende gesé oor grondvrugbaatheid: “...die verbouing van 'n bepaalde gewas op 'n bepaalde grond opvolggewasse kan affekteer as gevolg van de direkte en indirekte invloed wat dit mag hé op die voorraad plantvoedingstowwe en water in die grond, op die fisiese toestand van die grond, op erosie, asook op die voorkoms van onkruid, plae en siektes." Hierdie invloed is egter nie uniek nie. Vir die doel van hierdie artikel aanvaar ons dat hierdie invloed deur die kostekoëffisiënte weerspieël sal word.

- Laastens neem ons ook aan dat die optimale volgorde van gewasse 'n siklus vorm. Indien die oplossing oor 'n aantal jare verkry word, sê van jaar $A$ tot jaar $B$, beteken dit dat jaar $B+1$ nie in ag geneem word nie. In die praktyk beteken dit dat die boerdery by jaar $B$ eindig. Ons soek egter ' $n$ oplossing wat ad 
infinitum volgehou kan word - die enigste moontlikheid is 'n oplossingsiklus. Die optimale volgorde herhaal dus na 'n aantal jare.

\section{DIE WISKUNDIGE MODEL}

Gestel $i, j$ en $k$ is indekse wat die moontlike gewasse in die wisselboustelsel aandui. Laat daar $n$ sulke gewasse wees. Dan volg dat $i, j$ en $k$ die volgende waardes kan aanneem.

$$
\begin{aligned}
& i=1,2,3, \ldots, n \\
& j=1,2,3, \ldots, n \\
& k=1,2,3, \ldots, n
\end{aligned}
$$

Gestel $H$ is die totale oppervlakte waarop gewasse verbou kan word.

Gestel $x^{t}$ is 'n oppervlak met die volgende eienskappe. Gedurende jaar $t$ groei gewas i op die oppervlak. Gedurende jaar $(t-1)$ het gewas j op dié oppervlak gegroei en gedurende jaar $(t-2)$ het gewas $k$ op dié oppervlak gegroei.

Gestel $c_{m}$ is die wins per oppervlakte indien gewas $k$ (twee jaar gelede) opgevolg word deur gewas $j$ (een jaar gelede) en gewas $j$ weer opgevolg word deur gewas $i$ (vanjaar). Die simbool, $c_{\text {kn }}$, vorm dus 'n kostekoêffisiënt. Let op dat $c_{\text {... }}$ onafhanklik van tyd is.

Aanvaar die siklus het ' $n$ periode van $T$ jare. Dan is die gewasse van jaar $T+1$ dieselfde as die gewasse van jaar 1 . Dus volg dat

$$
\begin{aligned}
& 0 \equiv T \\
& 1 \equiv T+1 \text { ens. }
\end{aligned}
$$

'n Skematiese voorstelling van so ' $n$ siklus word in Figuur 2-1 gegee.

Die probleem kan nou soos volg geformuleer word:

$$
\begin{aligned}
& \text { Maks } z=\sum_{i=1}^{n} \sum_{j=1}^{n} \sum_{k=1}^{n} \sum_{t=1}^{T} c_{j \neq k} x_{i j k}^{t} \\
& \text { o.a. } \sum_{i=1}^{n} x_{j+k}^{t+1} \leq \sum_{i=1}^{n} x_{j k i}^{t} \quad \forall j, k, t \\
& \sum_{i=1}^{n} \sum_{j=1}^{n} \sum_{k=1}^{n} x_{j i t}^{t} \leq H \quad t=1,2,3, \ldots, T
\end{aligned}
$$




$$
x_{j, k}^{t} \geq 0 \quad \forall i, j, k, t
$$

Dit is duidelik dat die probleem as ' $n$ lineêre programmeringsprobleem (LP) geformuleer kan word. Die doelfunksie is die som van al die oppervlaktes waarop gewasse verbou word, vermenigvuldig met die ooreenkomstige kostekoëffisiënte per oppervlakte, wat dan die totale wins vir die siklus van $T$ jare gee.

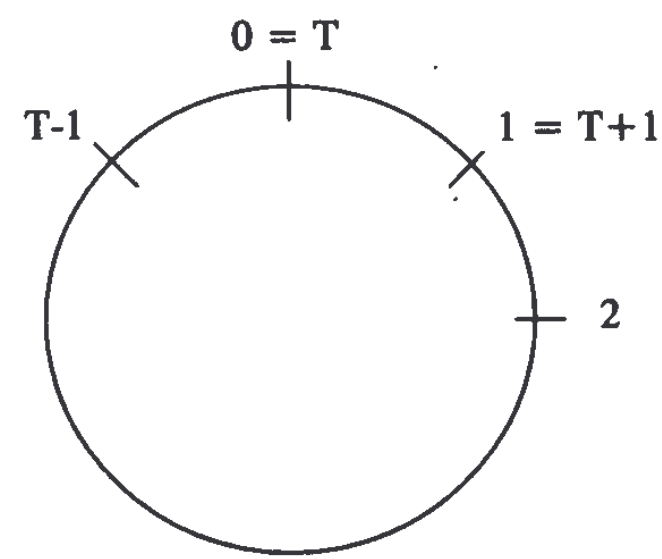

Figuur 2-1: Siklus van $T$ jare.

Die eerste beperking volg om die regte volgorde van gewasse te verseker, asook die regte oppervlaktes. Daarom word jaar $t+1$ beperk deur wat in jaar $t$ verbou is. As voorbeeld kan koring, klawer en hawer gebruik word. Alles wat in jaar $t+1$ op klawer op hawer gesaai kan word, moet kleiner of gelyk aan klawer op hawer op enige iets in jaar $t$ wees. Vandaar die vorm van die beperking, wat in der waarheid $n^{2} T$ beperkings is.

Die tweede beperking plaas 'n limiet op die totale oppervlakte waarop gewasse verbou kan word. Dit kan byvoorbeeld die grootte van die plaas wees. Vir die studie word die grootte $\mathrm{H}$ genoem.

Die derde en laaste beperking eis dat al die oppervlaktes positief is.

Dit is duidelik dat die triviale oplossing,

$$
x_{i k j}^{i}=0 \quad \forall i, j, k, t,
$$

'n oplossing van die LP in vergelykings (2.1) tot (2.3) is. Hierdie oplossing is egter nie 'n sinvolle oplossing nie. Dit voorspel dat die boer niks op niks moet doen nie. Deur beperking (2.3) as 'n gelyk aan beperking te skryf, word die triviale oplossing vermy en word die LP gedwing tot 'n sinvolle oplossing. Dit wil sê die LP word gedwing om 
oor die hele beskikbare oppervlak uitspraak te lewer. Die hele oppervlakte moet dus met een of ander gewas beplant word. (Let op dat geen gewas ook 'n moontlikheid kan wees.)

\section{Stelling 2.1}

Indien vergelykings (2.3) almal bindend is, volg dat vergelykings (2.2) ook almal bindend is.

Bewys Indien vergelykings (2.3) bindend is, volg dat

$$
\sum_{i=1}^{n} \sum_{j=1}^{n} \sum_{k=1}^{n} x_{i j k}^{t} \leq H \quad t=1,2,3, \ldots, T
$$

Gestel daar bestaan ten minste een $j, k$ en $t$ sê $l, k$ en $t$, waarvoor beperking (2.2) nie bindend is nie, dan volg dat

$$
\sum_{i=1}^{n} x_{i k^{\prime}}^{t^{\prime}+1}<\sum_{i=1}^{n} x_{j k^{\prime}}^{t^{\prime}}
$$

Dus

$$
\begin{aligned}
\sum_{i=1}^{n} \sum_{j=1}^{n} \sum_{k=1}^{n} x_{j k^{\prime}+1}^{g^{\prime}} & <\sum_{i=1}^{n} \sum_{j=1}^{n} \sum_{k=1}^{n} x_{i j k}^{t^{\prime}} \\
& =H,
\end{aligned}
$$

wat vergelyking (2.5) weerspreek.

QED

Die probleem soos deur vergelykings (2.1) tot (2.3) beskryf kan dus as volg herskryf word.

$$
\begin{aligned}
& \text { Maks } z=\sum_{i=1}^{n} \sum_{j=1}^{n} \sum_{k=1}^{n} \sum_{i=1}^{T} c_{i j k} x_{i k}^{t} \\
& \text { o.a. } \quad \sum_{i=1}^{n} x_{i j k}^{\ell+1}=\sum_{i=1}^{n} x_{j k i}^{t} \quad \forall j, k, t \\
& \sum_{i=1}^{n} \sum_{j=1}^{n} \sum_{k=1}^{n} x_{i j k}^{k}=H \quad t=1,2,3, \ldots, T \\
& x_{i j k}^{t} \geq 0 \quad \forall i, j, k, t
\end{aligned}
$$

Hierdie (primale) probleem kan, as daar baie gewasse is, baie groot word. Net die eerste beperking alleen bestaan uit $n^{2} T$ beperkings en $n^{3}$ veranderlikes. Om meer 
inligting oor die probleem in te win kan ons na die duale probleem [4] kyk. Laat $u_{\text {,k }}^{t}$ en $v^{t}$ die duale veranderlikes wees wat onderskeidelik met beperking (2.2) en (2.3) ooreenstem. Beide hierdie veranderlikes is gelyk aan beperkings wat impliseer dat al hierdie veranderlikes onbeperk in teken (t.o.) is. Let op dat al die primale beperkings van jaar $t$ aanleiding gee tot die boskrif $t$ by die duale veranderlike. Die duale probleem kan dan as volg geskryf word.

$$
\begin{aligned}
& \operatorname{Min} w=H \sum_{t=1}^{T} v^{t} \\
& \text { o.a. } \quad u_{k}^{t-1}-u_{i j}^{t}+v^{t} \geq c_{i j k} \quad \forall i, j, k, t=1,2,3 \ldots, T \\
& u_{i j}^{t},-u_{i j}^{t}+v_{j k}^{t} \quad \text { to. } \quad \forall i, j, k, t \\
& v^{t} \quad \text { t.o. } \quad \forall t
\end{aligned}
$$

Let op dat die boskrif van die veranderlike, $u_{k}^{k-1}$, in vergelyking 2.11$), t-1$ is. Indien die indeks $t=1$ is, beteken dit $t-1$ se waarde is $T$. Die boskrif word dus nie nul nie. Die gevalle $T=1,2$ en 3 word voorts beskou. Daarna gaan ons bewys dat ons nie beter kan doen as juis een van hierdie drie gevalle nie. Let op dat die primale probleem erg ontaard is. Dit beteken daar kan moontlik baie altematiewe duale oplossings vir elke primale oplossing wees. Dieselfde geld vir die duale probleem.

\section{Geval 1:}

Neem $T=1$. Dit impliseer dat die siklus net een jaar lank is. Dit wil sê dieselfde gewas word jaar na jaar op 'n spesifieke oppervlak geplant. Wiskundig beteken dit dat $i=j=k \equiv i$, sé. Verder is $T=1$. Die duale probleem se beperking vereenvoudig dan tot die volgende.

$$
\begin{array}{r}
u_{i}^{1}-u_{i}^{1}+v^{1} \geq c_{\text {tii }} \forall i \\
u_{i}^{1}, v^{1} \quad \text { t.o. } \forall \mathrm{i}
\end{array}
$$

Kies nou

$$
\begin{aligned}
\boldsymbol{v}^{1} & =\underset{i}{\operatorname{Maks}}\left\{c_{i i i}\right\} \\
& =c_{\text {mm. }} \text {. (sê) }
\end{aligned}
$$

Die waarde van die duale doelfunksie word dan

$$
w=H v^{1}=H c_{m m m} \text {. }
$$

Al die duale beperkings word bevredig. Die primale oplossing word dan

$$
x_{m m m}^{1}=H \text {. }
$$


Alle ander primale veranderlikes is nul. Die primale beperkings word dus bevredig. Verder volg dat

$$
\begin{aligned}
\text { Primale doelfunksie } & =H\left(C_{m m m}\right) \\
& =\text { Duale doelfunksie. }
\end{aligned}
$$

Dit impliseer dat ons 'n optimale oplossing oor een jaar het. Fisies beteken dit die boer moet elke jaar gewas $m$ plant.

\section{Geval 2:}

Neem $T=2$. In die geval word twee gewasse alternatiewelik op 'n spesifieke oppervlak geplant. Omdat slegs twee gewasse geplant word, loop die indekse slegs oor $i$ en $j$. Die beperkings van die duale probleem kan nou geskryf word as

$$
\begin{array}{lll}
t=1: & u_{j i}^{2}-u_{i j}^{1}+v^{1} \geq c_{i j i} \quad \forall i, j \\
& u_{j i}^{1}-u_{i j}^{2}+v^{2} \geq c_{i j i} \quad \forall i, j \\
& u_{i j}^{1}, u_{j i}^{1}, u_{i j}^{2}, u_{j j}^{2}, \text { t.o. }
\end{array}
$$

Vir vergelyking (2.15) kan die indekse kloksgewys geroteer word (Vir twee indekse beteken dit omgeruil word) sodat volg dat

$$
u_{i j}^{1}-u_{j i}^{2}+v^{2} \geq c_{j i j} \forall i, j .
$$

Tel (2.14) en (2.16) bymekaar, dan volg dat

$$
v^{1}+v^{2} \geq c_{t j}+c_{j i j}
$$

Kies $v^{1}+v^{2}$ as

$$
\begin{aligned}
v^{1}+v^{2} & =\underset{i j}{\operatorname{Maks}}\left\{c_{i j}+c_{j i j}\right\} \\
& =c_{\text {mmm }}+c_{n m n} \cdot \text { (sê) }
\end{aligned}
$$

In vergelyking (2.17) moet $m \neq n$. Hier ontstaan twee opvallende moontlikhede.

(i) Kies die oplossing as

$$
\begin{aligned}
& v^{1}=c_{m m m} \\
& v^{2}=c_{m m n} .
\end{aligned}
$$

Die u's in beperkings (2.14) en (2.16) kan maklik gevind word sodat dié beperkings ook bevredig word. Kies byvoorbeeld

$$
u_{i j}^{1}-u_{j i}^{2}=c_{m m}-c_{i j i} \quad \forall i, j .
$$


Vergelyking (2.14) word dan

$$
\begin{aligned}
v^{1} & \geq c_{i j i}+u_{i j}^{1}-u_{j i}^{2} \quad \forall i, j \\
& =c_{i j i}+c_{m m m}-c_{i j i} \\
& =c_{m m m}
\end{aligned}
$$

wat waar is. Dus word dié beperking bevredig. Beperking (2.16), vir die keuse hierbo, word dan

$$
\begin{aligned}
& v^{2} \geq c_{\text {jij }}-u_{i j}^{1}-u_{f i}^{2} \quad \forall i, j \\
& =c_{j i}+c_{\text {mmm }}-c_{i j i} \\
& ={ }_{i j}^{\text {Maks }}\left\{c_{i j i}+c_{i j i}\right\}-c_{\text {mmi }} \\
& =c_{\text {mmm }}+c_{\text {mm }}-c_{\text {mum }} \\
& =c_{\text {nmon }} \text {, }
\end{aligned}
$$

wat waar is. Dus word al die duale beperkings bevredig. Die duale doelfunksie is dus

$$
w=H\left(c_{\text {mm }}+c_{\text {man }}\right)
$$

Die ooreenkomstige primale oplossing word dus gegee deur

$$
\begin{aligned}
& x_{m-m}^{1}=H \\
& x_{n m}^{2}=H
\end{aligned}
$$

Al die ander veranderlikes is nul. Die oplossing bevredig al die primale beperkings. Let op dat $m \neq n$ moet wees. Indien nie, vereenvoudig dié geval na geval 1 . Vir dié oplossing is die waarde van die primale doelfunksie $H\left(C_{m m}+c_{n m n}\right)$. Die primale beperkings (2.2), (2.3) en (2.14) word ook bevredig. Let op dat

$$
\begin{aligned}
\text { Primale doelfunksie } & =H\left(c_{m-m}+c_{n m m}\right) \\
& =\text { Duale doelfunksie }
\end{aligned}
$$

Dit impliseer 'n optimale oplossing met 'n tweejaar-siklus. Fisies beteken die oplossing dat die boer in jaar 1 gewas $m$ en in jaar 2 gewas $n$ moet saai.

(ii) 'n Altematiewe optimale oplossing word verkry deur

$$
\begin{aligned}
v^{1}=v^{2} & =\frac{1}{2} \operatorname{Maks}_{i j}\left\{c_{i j}+c_{\text {iij }}\right\} \\
& =\frac{1}{2}\left(c_{\text {mm }}+c_{\text {mmn }}\right)
\end{aligned}
$$

te kies. Veranderlikes $u_{y}^{1}$ en $u^{2}$ kan maklik gevind word sodat die duale beperkings (2.14) ook bevredig word. Laat

$$
u_{i j}^{1}-u_{j i}^{2}=\frac{-c_{i j i}+c_{j i j}}{2} \forall i, j .
$$


Vir die keuse word beperking (2.14) gegee deur

$$
\begin{aligned}
v^{1} & \geq c_{i j i}+\frac{-c_{i j i}+c_{i j i}}{2} \quad \forall i, j \\
& =\frac{c_{i j}+c_{i j i}}{2} \\
& =\operatorname{Maks}_{i j}\left\{\frac{c_{i j i}+c_{j i j}}{2}\right\} \\
& =\frac{c_{\text {man }}+c_{m}}{2},
\end{aligned}
$$

wat waar is. Beperking (2.16) word dan gegee deur

$$
\begin{aligned}
v^{2} & \geq c_{j i}+\frac{-c_{i j i}+c_{j j i}}{2} \forall i, j \\
& =\frac{c_{j i j}+c_{i j i}}{2} \\
& =\operatorname{Maks}_{i j}\left\{\frac{c_{i j}+c_{i j i}}{2}\right\} \\
& =\frac{c_{m m}+c_{m m}}{2},
\end{aligned}
$$

wat waar is. Al die duale beperkings word dus bevredig. Vir hierdie keuse volg dat

$$
\begin{aligned}
\text { Duale doelfunksie } & =H\left(v^{1}+v^{2}\right) \\
& =H\left(c_{\text {m }}+c_{\text {nmon }}\right) .
\end{aligned}
$$

Die primale oplossing wat hiermee ooreenstem is:

$$
\begin{aligned}
& x_{\operatorname{mm}}^{1}=\frac{H}{2} \\
& x_{m=\frac{H}{2}}^{1}=\frac{H}{2} \\
& x_{\operatorname{mm}}^{2}=\frac{H}{2} \\
& x_{m=\frac{H}{2}}^{2} .
\end{aligned}
$$

Al die ander veranderlikes se waarde is nul. Hierdie oplossing bevredig die primale beperkings.

$$
\begin{aligned}
\text { Primale doelfunksie } & =\frac{H}{2} c_{m m m}+\frac{H}{2} c_{m m n}+\frac{H}{2} c_{m m m}+\frac{H}{2} c_{n m m} \\
& =H\left(c_{m m}+c_{m m}\right) \\
& =\text { Duale doelfunksie. }
\end{aligned}
$$

Hierdie is dus ook 'n optimale oplossing vir 'n tweejaar-siklus. Fisies beteken dit nog steeds 'n tweejaar-siklus, elke spesifieke stuk grond is ondenworpe aan 'n tweejaar- 
siklus. Dit wil sê, die grond word gehalveer. Op elke halwe word die twee gewasse gealterneer. Dit word skematies in Figuur 2-2 voorgestel.
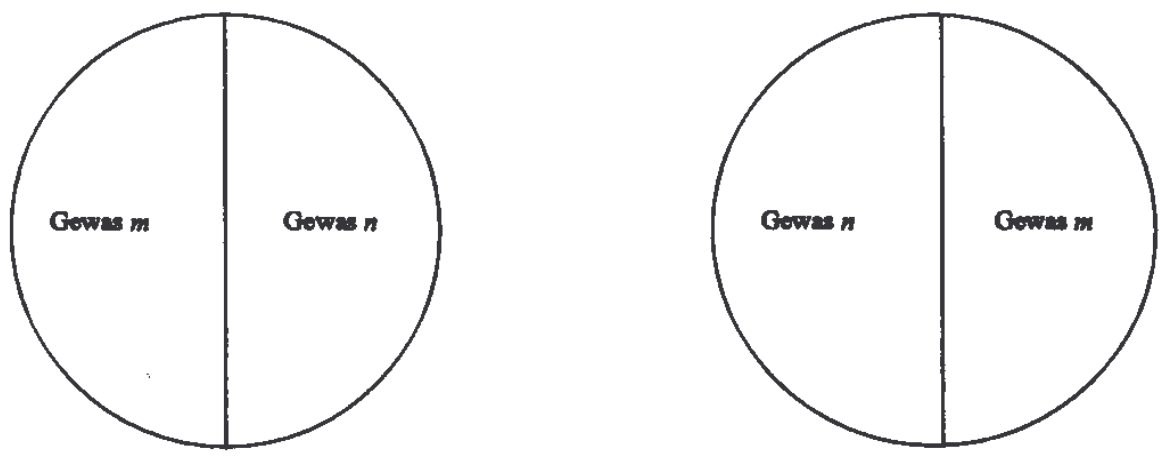

Figuur 2-2: Skematiese voorstelling van die rotasie in 'n optimale tweejaar-siklus.

Let op dat enige konvekse kombinasie van twee optimale oplossings, soos hierto gegee, ook 'n optimale oplossing vir die probleem sal wees. Byvoorbeeld

\begin{tabular}{|c|c|c|c|}
\hline & $\underline{x}^{1}$ & $\underline{x}^{2}$ & $\frac{1}{2} \underline{x}^{1}+\frac{1}{2} x^{2}$ \\
\hline$x_{-m}^{1}$ & $H$ & $\frac{H}{2}$ & $\frac{H}{2}+\frac{1}{2}\left(\frac{H}{2}\right)=\frac{3 H}{4}$ \\
$x_{n-m}^{1}$ & 0 & $\frac{H}{2}$ & $0+\frac{1}{2}\left(\frac{H}{2}\right)=\frac{H}{4}$ \\
\hline$x_{-m}^{2}$ & 0 & $\frac{H}{2}$ & $0+\frac{1}{2}\left(\frac{H}{2}\right)=\frac{B}{4}$ \\
$x_{m}^{2}$ & $H$ & $\frac{H}{2}$ & $\frac{H}{2}+\frac{1}{2}\left(\frac{H}{2}\right)=\frac{3 H}{4}$ \\
\hline
\end{tabular}

Fisies beteken dit dat die boer in jaar 1 ' $n$ kwart $n$ en ' $n$ driekwart $m$ saai. In jaar 2 saai die boer ' $n$ kwart $m$ en 'n driekwart $n$.

\section{Geval 3:}

Laat $T=3$. in die geval word die duale beperkings gegee deur

$$
\begin{array}{r}
u_{j k}^{3}-u_{i j}^{1}+v^{1} \geq c_{i, k} \forall i, j, k \\
u_{j k}^{1}-u_{i j}^{2}+v^{2} \geq c_{i, k} \forall i, j, k \\
u_{k}^{2}-u_{i j}^{3}+v^{3} \geq c_{i, k} \forall i, j, k \\
u_{i j}^{1}, u_{j k}^{1}, u_{i j}^{2}, u_{k k}^{2}, u_{i j}^{3}, u_{k}^{3}, v^{1}, v^{2}, v^{3}
\end{array}
$$

Figuur 2-3: Koksgewyse rotasie van $i, j$ en $k$. 
Deur $i$, $j$ en $k$ kloksgewys te roteer volgens Figuur 2-3 kan vergelykings (2.20) en (2.21) herskryf word tot

$$
\begin{array}{lc}
u_{k i}^{1}-u_{k}^{2}+v^{3} \geq c & \forall i, j, k \\
u_{i j}^{2}-u_{k j}^{3}+v^{3} \geq c_{k j j} & \forall i, j, k .
\end{array}
$$

As vergelykings (2.19), (2.22) en (2.23) bymekaar getel word volg dat

$$
v^{1}+v^{2}+v^{3} \geq c_{i j k}+c_{j i k}+c_{k j j} \quad \forall i, j, k
$$

Laat

$$
\begin{aligned}
& v^{1}+v^{2}+v^{3}=\underset{i j k}{\operatorname{Maks}}\left\{c_{i j k}+c_{j \neq}+c_{k j}\right\} \\
& c_{\text {met }}+c_{\min }+c_{i m i n} .
\end{aligned}
$$

Hier ontstaan ook twee opvallende moontlikhede.

(i) Laat

$$
\begin{aligned}
v^{1} & =c_{\text {mut }} \\
v^{2} & =c_{\text {mb }} \\
v^{3} & =c_{\text {m n }} .
\end{aligned}
$$

Die $u$-veranderlikes kan soos hieronder gekies word om beperkings $(2,19),(2,22)$ en $(2,23)$ te bevredig. Laat

$$
\begin{aligned}
& u_{j k}^{3}-u_{i v}^{1}=-c_{m}+c_{\text {t* }} \quad \forall i, j, k \\
& u_{k t}^{1}-u_{k}^{2}=-c_{\text {mit }}+c_{\text {jit }} \\
& u_{i j}^{2}-u_{t i}^{3}=-c_{i t}-c_{j i}+c_{m i d}+c_{\text {nim }} \text {. }
\end{aligned}
$$

Hieruit volg dat

$$
\begin{aligned}
& v^{1} \geq c_{\text {m }} \\
& v^{2} \geq c_{\text {nam }} \\
& v^{3} \geq c_{k j j}+c_{\text {int }}+c_{\text {jij }}-c_{\text {mal }}-c_{\text {nm }} \quad \forall i, j, k
\end{aligned}
$$

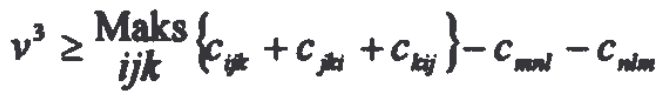

$$
\begin{aligned}
& v^{3} \geq c_{\text {bm }} \text {. }
\end{aligned}
$$

Die duale beperkings word dus bevredig. Hieruit is dit duidelik dat

$$
\text { Duale doelfunksie }=H\left(c_{m}+c_{\operatorname{nim}}+c_{\operatorname{mm}}\right)
$$


Die ooreenkomstige primale oplossing is

$$
\begin{aligned}
& x_{m i l}^{1}=H \\
& x_{n i m}^{2}=H \\
& x_{l m n}^{3}=H .
\end{aligned}
$$

Al die ander veranderlikes is nul. Die primale beperkings word ook bevredig en

$$
\begin{aligned}
\text { Primale doelfunksie } & =H\left(c_{m+1}+c_{n m m}+c_{\mathrm{mm}}\right) \\
& =\text { Duale doelfunksie. }
\end{aligned}
$$

Fisies beteken dit dat die boer in jaar 1 gewas $m$, in jaar 2 gewas $n$ en in jaar 3 gewas I moet plant. 'n Skematiese voorstelling van die oplossing word hieronder gegee.

(ii) Vir die tweede moontlikheid, laat

$$
\begin{aligned}
& v^{1}=\frac{1}{3}\left(c_{m u}+c_{n-m}+c_{\text {mon }}\right) \\
& v^{2}=\frac{1}{3}\left(c_{\text {mit }}+c_{\text {m }}+c_{\text {m }}\right) \\
& v^{3}=\frac{1}{3}\left(c_{\text {max }}+c_{\text {mat }}+c_{\text {bm }}\right)
\end{aligned}
$$

Die u-veranderlikes kan byvoorbeeld soos hieronder gekies word om beperkings ((2.19), (2.22) en (2.23) te bevredig.

$$
\begin{aligned}
& u_{k}^{3}-u_{i j}^{1}=\frac{2}{3} c_{i k}-\frac{1}{3} c_{j i j}-\frac{1}{3} c_{k j i} \forall i, j, k \\
& u_{k i}^{1}-u_{j k}^{2}=\frac{2}{3} c_{j t}-\frac{1}{3} c_{*}-\frac{1}{3} c_{k j} \forall i, j, k \\
& u_{i j}^{2}-u_{k j}^{3}=\frac{2}{3} c_{k j}-\frac{1}{3} c_{j i j}-\frac{1}{3} c_{i k j} \forall i, j, k
\end{aligned}
$$

Vanaf beperking (2.19) volg dat

$$
\begin{aligned}
& v^{1}=c_{i j k}-u_{j k}^{0}+u_{i j}^{1} \quad \forall i, j, k \\
& =c_{* *}-\left[\frac{2}{3} c_{*}-\frac{1}{3} c_{*}-\frac{1}{3} c_{t j}\right] \forall i, j, k
\end{aligned}
$$

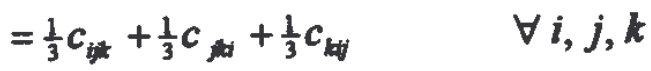

$$
\begin{aligned}
& =\underset{i j k}{\text { Maks }}\left\{\frac{1}{3} c_{i k}+\frac{1}{3} c_{j \neq}+\frac{1}{3} c_{k j}\right\} \forall i, j, k
\end{aligned}
$$

Beperking (2.19) word dus bevredig. Daar kan op soortgelyke wyse bewys word beperkings (2.22) en (2.23) bevredig word. Vir die oplossing word die duale doelfunksie gegee deur

$$
\text { Duale doelfunksie }=H\left(c_{m, 1}+c_{m m}+c_{m m}\right)
$$


Die primale oplossing wat hiermee ooreenstem is

$$
\begin{array}{lll}
x_{m n l}^{1}=\frac{H}{3} & x_{m n l}^{2}=\frac{H}{3} & x_{m n l}^{3}=\frac{H}{3} \\
x_{m l m}^{1}=\frac{H}{3} & x_{m l m}^{2}=\frac{H}{3} & x_{n l m}^{3}=\frac{H}{3} \\
x_{l m n}^{1}=\frac{H}{3} & x_{l m n}^{2}=\frac{H}{3} & x_{l m n}^{3}=\frac{H}{3} .
\end{array}
$$

Al die ander veranderlikes is nul. Die primale doelfunksie word dan

$$
\text { Primale doelfunksie } \quad \begin{aligned}
& =\frac{H}{3} c_{m n l}+\frac{H}{3} c_{n l m}+\frac{H}{3} c_{l m n} \\
& +\frac{H}{3} c_{m n l}+\frac{H}{3} c_{n l m}+\frac{H}{3} c_{l m n} \\
& +\frac{H}{3} c_{m n l}+\frac{H}{3} c_{n l m}+\frac{H}{3} c_{l m n} \\
& =H\left(c_{m n l}+c_{n l m}+c_{l m n}\right) \\
& =\text { Duale doelfunksie }
\end{aligned}
$$

Dit impliseer dat ons hier 'n alternatiewe optimale oplossing het. Hierdie strategie is ekwivalent aan die geval hierbo. Alhoewel elke spesifieke oppervlak onderworpe is aan 'n driejaar-siklus, bly die strategie elke jaar dieselfde $\mathrm{nl}$. 'n derde van die oppervlakte word met $m$ geplant, ' $n$ derde met $n$ en 'n derde met $I$. Dit word skematies in Figuur 2-4 voorgestel.

$$
\begin{array}{r}
\text { Jaar } 1 \\
\text { Jaar } 2 \\
\text { Jaar } 3
\end{array}
$$

\begin{tabular}{|l|l|l|}
\hline Gewas $m$ & Gewas $n$ & Gewas $/$ \\
\hline Gewas $/$ & Gewas $m$ & Gewas $n$ \\
\hline Gewas $n$ & Gewas $n$ & Gewas $m$ \\
\hline
\end{tabular}

Figuur 2-4: Skematiese voorstelling van die strategie vir die driejaar-siklus.

Let op dat enige konvekse kombinasie van twee optimale oplossings ook 'n optimale strategie lewer. 


\begin{tabular}{|c|c|c|c|}
\hline & $\underline{x}^{1}$ & $\underline{x}^{2}$ & $\frac{1}{2} \underline{x}^{1}+\frac{1}{2} \underline{x}^{2}$ \\
\hline$x_{m n l}^{1}$ & $H$ & $\frac{H}{3}$ & $\frac{H}{2}+\frac{1}{2}\left(\frac{H}{3}\right)=\frac{2 H}{3}$ \\
$x_{n l m}^{1}$ & 0 & $\frac{H}{3}$ & $\frac{0}{2}+\frac{1}{2}\left(\frac{H}{3}\right)=\frac{H}{6}$ \\
$x_{l m n}^{1}$ & 0 & $\frac{H}{3}$ & $\frac{0}{2}+\frac{1}{2}\left(\frac{H}{3}\right)=\frac{H}{6}$ \\
\hline$x_{m m l}^{2}$ & 0 & $\frac{H}{3}$ & $\frac{0}{2}+\frac{1}{2}\left(\frac{H}{3}\right)=\frac{H}{6}$ \\
$x_{m l m}^{2}$ & $H$ & $\frac{H}{3}$ & $\frac{H}{2}+\frac{1}{2}\left(\frac{H}{3}\right)=\frac{2 H}{3}$ \\
$x_{l m n}^{2}$ & 0 & $\frac{H}{3}$ & $\frac{0}{2}+\frac{1}{2}\left(\frac{H}{3}\right)=\frac{H}{6}$ \\
\hline$x_{m n l}^{3}$ & 0 & $\frac{H}{3}$ & $\frac{0}{2}+\frac{1}{2}\left(\frac{H}{3}\right)=\frac{H}{6}$ \\
$x_{n l m}^{3}$ & 0 & $\frac{H}{3}$ & $\frac{0}{2}+\frac{1}{2}\left(\frac{H}{3}\right)=\frac{H}{6}$ \\
$x_{l m n}^{3}$ & $H$ & $\frac{H}{3}$ & $\frac{H}{2}+\frac{1}{2}\left(\frac{H}{3}\right)=\frac{2 H}{3}$ \\
\hline
\end{tabular}

Hierdie oplossings lewer almal presies dieselfde wins.

In die res van die dokument werk ons met die oplossing wat so is dat die boer elke jaar dieselfde grootte van elke gewas plant. Dit wil sê helfte, helfte in die geval 'n tweejaar-siklus en 'n derde, derde, derde in die geval van 'n driejaar-siklus. In die gevalle is die oplossings onafhanklik van die tyd, $t$.

Die veralgemening vir $T=4,5, \ldots$ ensovoorts volg op soortgelyke wyse. In die algemeen sal ' $n$ optimale oplossing afhang van beide $T$ en $n$. Die waarde van $T$ kan egter nie onbeperk toeneem nie. Die redes hiervoor kan as volg gelys word.

- Uit 'n wiskundige oogpunt word die probleem vinnig groter met toename in $T$. Dus om die probleem in ' $n$ hanteerbare grootte te hou, sal $T$ iewers afgekap moet word.

- Uit 'n praktiese oorweging kan geredeneer word dat die pryse van die gewasse ter sprake nie konstant bly nie. Dit sal dus vir die boer onprakties wees om hom in 'n baie lang siklus te laat vasvang. As die prys van koring byvoorbeeld in die middel van ' $n$ siklus baie val en koring vorm ' $n$ groot deel van die bestaande siklus sal die boer moontlik na 'n ander siklus moet verander. Hoe langer so ' $n$ siklus is, hoe groter is die kans vir 'n groot genoeg prysverandering sodat die huidige siklus nie meer ' $n$ optimale siklus is nie.

- In die praktyk word daar selde van siklusse langer as twee jaar gebruik gemaak. 
As die bostaande redes bekou word, moet nog 'n aanname gemaak word. Vir die doeleindes van hierdie artikel gaan slegs siklusse van drie jaar en korter beskou word. Dit wil sê ons werk met die geval $T \leq 3$.

Teen die agtergrond van dié aanname kan daar nou strategieë soos in $\S 3$ gedefinieer word.

\section{STRATEGIEË}

Indien die oplossings soos in die vorige afdeling voorgestel, gebruik word, sal 'n optimale oplossing in alle gevalle onafhanklik van die tyd wees. Daarom laat ons vir die res van die werk die boskrif $t$ weg.

Definieer nou vir die drie gevalle drie strategieë.

$$
\begin{aligned}
S_{i}^{\prime} & =x_{i i i} & & \forall i \\
S_{i j}^{\prime} & =\frac{1}{2}\left(x_{i j i}+x_{j i j}\right) & & \forall i, j \\
S_{i j k}^{\prime} & =\frac{1}{3}\left(x_{i j k}+x_{j k i}+x_{k i j}\right) & & \forall i, j, k
\end{aligned}
$$

Let op dat 'n strategie, bv. $S_{i j k}^{\prime}$, ooreenstem met die totale grootte van die oppervlakte waarop die strategie toegepas word. Gestel byvoorbeeld $S_{123}^{\prime}=30$ hektaar, dan volg dat die boer elke jaar 10 hektaar van gewas 1, 10 hektaar van gewas 2 en 10 hektaar van gewas 3 moet plant. Definieer ooreenkomstige kostekoëffisiënte vir elke strategie.

$$
\begin{array}{rlrl}
\gamma_{i}^{\prime} & =c_{i i j} & & \forall i \\
\gamma_{i j}^{\prime} & =\frac{1}{2}\left(c_{i j i}+c_{j i j}\right) & & \forall i, j \\
\gamma_{i j k}^{\prime} & =\frac{1}{3}\left(c_{j j k}+c_{j k i}+c_{k j j}\right) & \forall i, j, k
\end{array}
$$

Die kostekoëffisiënt stem dus ooreen met die wins wat die boer (per jaar) uit die ooreenstemmende strategie maak. 
Die probleem kan nou as volg geformuleer word (vir alle $i, j$ en $k$ ):

$$
\begin{aligned}
\text { Maks } z=\sum_{i} \gamma_{i}^{\prime} S_{i}^{\prime}+\sum_{i j} \gamma_{i j}^{\prime} S_{i j}^{\prime}+\sum_{i j k} \gamma_{i j k}^{\prime} S_{i j k}^{\prime} & \\
\text { o.a. } \quad \sum_{i} S_{i}^{\prime}+\sum_{i j} S_{i j}^{\prime}+\sum_{i j k} S_{i j k}^{\prime} & =H \\
S_{i j}^{\prime} & \geq 0 \\
S_{i j}^{\prime} & \geq 0 \\
S_{i j k}^{\prime} & \geq 0
\end{aligned}
$$

Ons noem die probleem vir verdere verwysing probleem twee. Beperking (2.2) val nou weg omdat elke strategie reeds die beperking bevredig.

\section{Definisie 3.1}

Twee strategiee is ekwivalent (झ) indien beide strategiee dieselfde oplossing vir probleem twee verteenwoordig.

Dit is byvoorbeeld duidelik dat

$$
\begin{array}{rlrl}
S_{i}^{\prime} \equiv S_{i i i}^{\prime} & & \forall i \\
S_{i j}^{\prime} & \equiv S_{j i}^{\prime} & & \forall i, j \\
S_{i j k}^{\prime} \equiv S_{j k i}^{\prime} \equiv S_{k i j}^{\prime} & \forall i, j, k
\end{array}
$$

Die versameling, $S^{\prime}$, van al die moontlike strategieë is reeds gedefinieer as

$$
S^{\prime}=\left\{S_{i}^{\prime}, S_{i j}^{\prime}, S_{i j k}^{\prime}\right\}
$$

Dit is ook duidelik dat definisie 3.1 'n ekwivalensierelasie([1], [2]) oor die versameling van al die strategieë is en dus ' $n$ partisie van die strategieë veroorsaak. Alle nieekwivalente strategieë word saam gegroepeer in die partisie (die sogenaamde reduksie partisie). Die bepaling van die reduksie partisie is in hierdie geval triviaal. Laat, $S=\left\{S_{i}, S_{i j}, S_{i j k}\right\}$, die versameling nie-ekwivalente strategieë wees met elemente $S_{i}, S_{i j}, S_{j i k}$ en ooreenkomstige kostekoëffisiënte, $\gamma_{i}, \gamma_{i j}, \gamma_{i j k}$. Probleem twee kan nou as volg herskryf word.

$$
\begin{aligned}
\text { Maks } z=\sum_{i} \gamma_{i} S_{i}+\sum_{i j} \gamma_{i j} S_{i j}+\sum_{i j k} \gamma_{i j k} S_{i j k} & \\
\text { o.a. } \quad \sum_{i} S_{i}+\sum_{i j} S_{i j}+\sum_{i j k} S_{i j k} & =H \\
S_{i} & \geq 0 \\
S_{i j} & \geq 0 \\
S_{i j k} & \geq 0
\end{aligned}
$$


Hierdie is ' $n$ eenvoudiger probleem. Dit is ' $n$ spesiale geval van die rugsakprobleem[4]. Aangesien daar slegs een beperking is, beteken dit dat daar slegs een veranderlike, $S(i)$, in die optimale oplossing is. Dit sal die $S(i)$ wees met die grootste kostekoëffisiënt.

\subsection{Voorbeeld}

Hier volg 'n voorbeeld om die voorafgaande werk te illustreer. Die volgende word gegee.

\begin{tabular}{ll}
$i j k$ & $c_{i j k}$ \\
\hline 111 & 4 \\
112 & 5 \\
121 & 6 \\
122 & 6 \\
211 & 5 \\
212 & 5 \\
221 & 6 \\
222 & 5 \\
\hline
\end{tabular}

Bepaal die ekwivalente strategieë. Doen dit deur alle strategieë vir een-, twee- en driejaar-siklusse neer te skryf. Bepaal elke nuwe strategie se $\gamma(i)$ en merk die strategieë wat ekwivalent is aan ' $n$ vorige een met ' $n \times$. 


\begin{tabular}{l|ll}
$S$ & Strategie & $\gamma$ \\
$S_{1}$ & Eenjaar-siklus & \\
$S_{2}$ & 2 & 4 \\
$S_{12}$ & Tweejaar-siklus & 5 \\
$\times 11$ & $\times$ \\
12 & $\frac{c_{122}+c_{212}}{2}=\frac{6+5}{2}=5,5$ \\
$S_{112}$ & $\times 21$ & $\times$ \\
$\times 22$ & $\times$ \\
$S_{122}$ & $\times \frac{c_{122}+c_{211} c_{121}}{3}=\frac{5+5+6}{3}=5,333$ \\
$\times 112$ & $\times$ \\
$\times 121$ & $\frac{c_{122}+c_{212} c_{221}}{3}=\frac{6+5+6}{3}=5,666$ \\
122 & $\times$ \\
$\times 211$ & $\times$ \\
$\times 212$ & $\times$ \\
$\times 221$ & $\times$ \\
$\times 222$ & $\times$
\end{tabular}

Kies die strategie met die grootste $\gamma$. Dit lewer die optimale strategie. Die optimale strategie is dus $S_{122}$. Die oplossing is dus

$$
\begin{aligned}
& x_{122}=\frac{H}{3} \\
& x_{212}=\frac{H}{3} \\
& x_{221}=\frac{H}{3} .
\end{aligned}
$$

As $c_{112}=4$ en $c_{221}=5$, dan maak ons die $c^{\prime}$ s net van twee jaar afhanklik Byvoorbeeld $c_{121}=c_{122}=6$, ens. Dit veroorsaak dan dat 'n tweejarige siklus dile optimaal gee, $\mathrm{nl} . S_{12}$. 


\subsection{Toepassing}

In die Koeberg gebied in Wes-Kaap word 'n studiegroep deur die plaaslike boerevereniging bedryf om die boere voorligting te gee in sake gewas strategië. Elke produsent teken alle kostes en inkomstes ten op sigte van elke gewas wat geplant word met behulp van 'n eenvoudige rekenaarstelsel aan. Alle inligting word sentraal verwerk en sodanig word 'n databank opgebou met wins syfers ten opsigte van alle moontlike strategië. Terugvoering word jaarliks aan die boere gegee. Ongeveer 3000 ha word jaarliks gemonitor en data word reeds die afgelope 8 jaar ingesamel.

\section{VERWYSINGS}

[1] Halmos, P.R., (1960) Naive Set Theory, D. van Nostrand Company, Inc., Princeton.

[2] Kolman, B., Busby R.C., (1987) Discrete Mathematical Structures for Computer Science, Second Edition, Prentice-Hall, Inc., Englewood Cliffs, New Jersey.

[3] Wassermann, V.D., (1982) Wisselbou en Grondvrugbaarheid, Blad van Eendaagse Kleingraanjaarsimposium, Kleingraan Ontwikkelingsvereniging, Stellenbosch.

[4] Zionts, S., (1974) Linear and Integer Programming, Prentice-Hall Inc., Inglewood Cliffs, New Jersey. 